
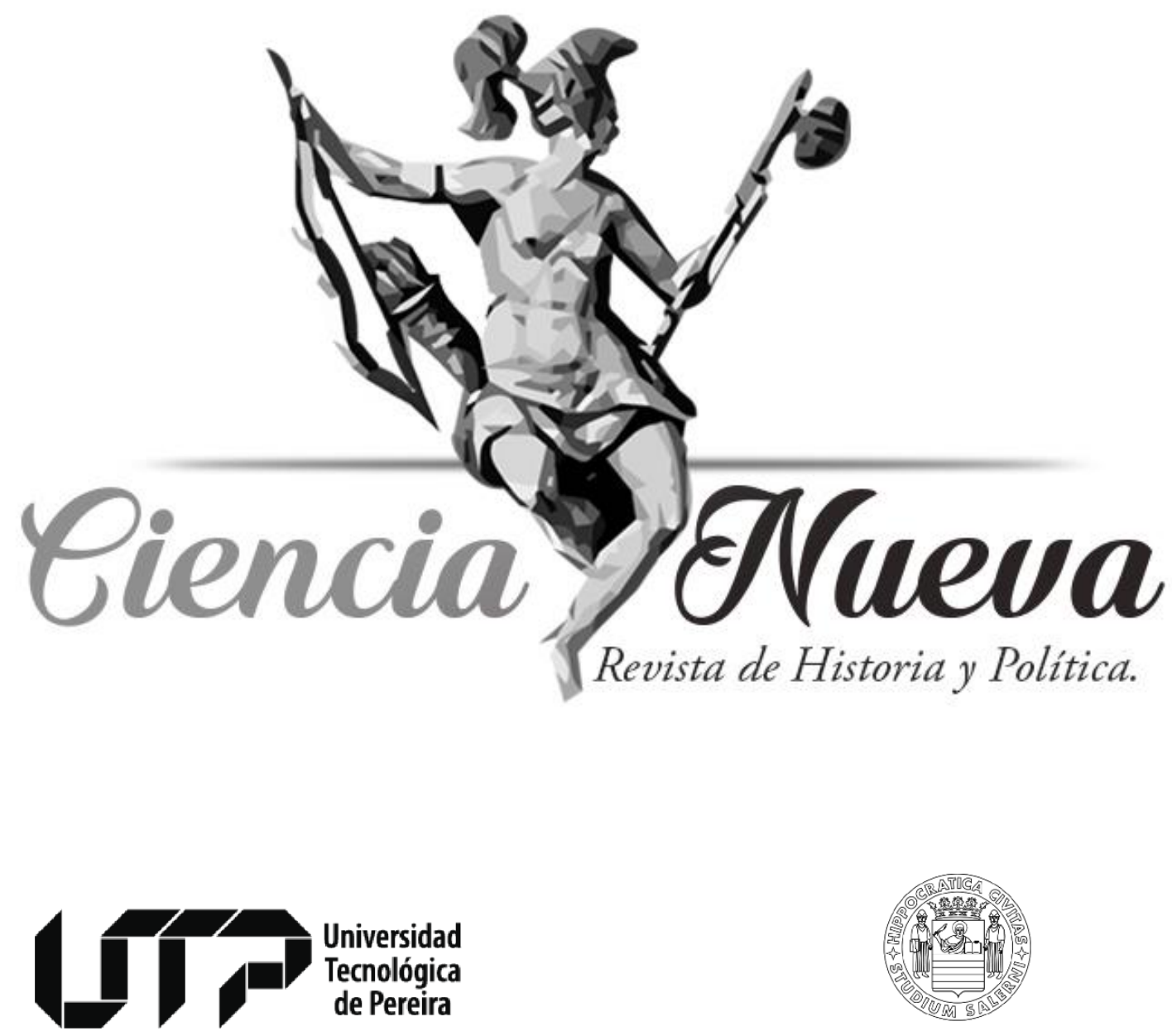

UNIVERSITÀ DEGLI STUDI DI SALERNO

Maestría en Historia

Maestría en Ciencia Política

RESEÑAS

ORLANDO VILLANUEVA MARTÍNEZ, CANCIONES DE LA GUERRA. LA INSURRECCIÓN LLANERA CANTADA Y DECLAMADA (BOGOTÁ: UNIVERSIDAD DISTRITAL FRANCISCO JOSÉ DE CALDAS, 2016), 390 PP. ORLANDO VILLANUEVA MARTÍNEZ, SONGS OF WAR. THE LLANEROS INSURRECTION SUNG AND DECLAIMED (BOGOTÁ: UNIVERSIDAD DISTRITAL FRANCISCO JOSÉ DE CALDAS, 2016),

José Abelardo Díaz Jaramillo pp. $157-160$

Vol. $1 N^{o}$ 2, Julio-Diciembre de 2017 Pereira, Colombia 


\section{ORLANDO VILLANUEVA MARTÍNEZ, CANCIONES DE LA GUERRA. LA INSURRECCIÓN LLANERA CANTADA Y DECLAMADA (BOGOTÁ: UNIVERSIDAD DISTRITAL FRANCISCO JOSÉ DE CALDAS, 2016), 390 PP.** ORLANDO VILLANUEVA MARTÍNEZ, SONGS OF WAR. THE LLANEROS' INSURRECTION SUNG AND DECLAIMED (BOGOTÁ: UNIVERSIDAD DISTRITAL FRANCISCO JOSÉ DE CALDAS, 2016, 390 PP.}

$\begin{aligned} & \begin{array}{r}\text { José Abelardo Díaz Jaramillo** } \\ \text { jose.diaz@ unimeta.edu.co }\end{array} \\ & \text { ORCID: https://orcid.org/0000-0001-8279-2379 }\end{aligned}$

$\mathrm{L}$

a violencia política que se registró en Colombia a mediados del siglo $\mathrm{XX}$, tuvo en las guerrillas liberales de los llanos orientales una de sus expresiones más acabadas. En efecto, entre 1948 y 1953, se originó en el extenso territorio oriental del país un poderoso movimiento de resistencia popular armada, que se constituyó en una amenaza para la estabilidad del régimen político. Una interpretación histórica de esa expresión social fue realizada por Villanueva Martínez en el marco de sus estudios de doctorado, obra publicada en 2012. ${ }^{1}$ En esta ocasión, el autor vuelve a los mismos hechos de los que se ocupó en aquella oportunidad, pero esta vez explorando una faceta que no había sido abordada hasta ahora desde una perspectiva analítica: la producción y difusión de cantos y poemas durante y después del levantamiento armado.

Para tal fin, el libro está dividido en dos partes. En la primera, además de un sugerente prólogo elaborado por el profesor Hermes Tovar Pinzón, encontramos una presentación general del tema, en donde el autor plantea un conjunto de tesis sobre la relación entre las composiciones musicales y la insurrección armada en los llanos orientales. La segunda parte reúne 90 canciones y 65 poemas (con referencias a pie de página que precisan el origen de la composición, su autor y las circunstancias históricas que evocan), y tres tablas que describen los contenidos, ritmos musicales y compositores. En la parte final hay una galería de imágenes referidas a hechos ocurridos en la primera mitad del siglo XX (por ejemplo, la guerra de los mil días y el asesinato de Gaitán) y de la violencia política en los llanos orientales; y un glosario de términos regionales mencionados en las canciones y los poemas. 2

Como es comprensible, uno de los aspectos más importantes de la publicación tiene que ver con la interpretación del origen y la función de las decenas de canciones y poemas

\footnotetext{
* El presente artículo respeta las directrices y normas dispuestas en la Declaración de Ética de Publicación de Ciencia Nueva, Revista de Historia y Política. Esta declaración puede consultarse en la página web de la revista: revistas.utp.edu.co/index.php/historia

** Magister en Historia de la Universidad Nacional de Colombia. Estudiante del Doctorado en Historia de la Universidad Nacional de Colombia. Profesor de la Corporación Universitaria del Meta.

${ }^{1}$ Orlando Villanueva Martínez, Guadalupe Salcedo y la insurrección llanera, 1949 - 1957 (Bogotá: Universidad Nacional de Colombia, 2012).

${ }^{2}$ El libro viene acompañado de un CD editado por al Ministerio de Cultura, compila doce canciones, once videos musicales y siete entrevistas y testimonios colectivos enfocados a la relación entre canción e insurrección llanera.
} 
que circularon de manera oral en aquellos años, e incluso todavía hoy, como se puede constatar al visitar algunos lugares de la región. Para avanzar en esa dirección, el autor establece, a nuestro juicio de manera un poco desordenada e incluso repetitiva, un conjunto de tesis que, para fines expositivos, agrupamos en tres bloques: las referidas a las funciones de las canciones y los poemas alusivos a la insurrección llanera, las referidas a las circunstancias sociales e históricas en que fueron elaborados, y las referidas a los hechos o situaciones que fueron evocados con más insistencia en las composiciones.

Acerca de las funciones de las canciones y los poemas, Villanueva Martínez establece que las composiciones tuvieron desde un comienzo propósitos múltiples. El que más destaca fue contar y cantar la insurrección llanera. Gracias a las letras, que eran acompañadas en muchas ocasiones con música, se pudo conocer lo que ocurría en el territorio, e incluso, como lo indica el autor, terminaron convertidas "en el periódico de los analfabetos y en el noticiero de los pueblos". De ese modo, los habitantes del extenso territorio pudieron tener conocimiento, por ejemplo, de las acciones guerrilleras como la toma de pueblos, cuarteles militares, emboscadas a convoyes, voladuras de puentes y carreteras. Pero también las canciones y los poemas tuvieron como función la generación de un ambiente favorable en la lucha que libraban los rebeldes en las llanuras y servían de instrumento de politización entre la población. Al respecto, el autor nos recuerda que muchos de los compositores de los cantos y poemas fueron individuos que actuaron como secretarios de los comandos armados, como miembros de las guerrillas o fueron simples simpatizantes de las mismas. De manera que este acervo musical y poético, además de haber sido un mecanismo de resistencia en medio de una feroz confrontación armada, sirvió también para popularizar el movimiento que se gestó y permitió la exaltación del regionalismo (un componente identitario clave para entender la fortaleza anímica del levantamiento), así como la preservación en la memoria colectiva del papel de los combatientes y de sus acciones.

Sobre la circunstancia social de las composiciones, el segundo bloque de la tesis, el autor destaca el corrido como una construcción colectiva, cuyos autores acudieron en muchas ocasiones al anonimato como una forma de proteger sus vidas. Generalmente se transmitieron de manera oral, lo que explicaría la diversidad e incluso la desfiguración de las letras en relación con las versiones originales, aspecto que volveremos a tratar más adelante. El autor indica que por las circunstancias de su producción y por haberse tratado de discursos ocultos, los títulos, actores y fechas de creación, en la mayoría de los casos, son imposibles de identificar o precisar. Hay que decir que, en este punto, el autor insiste en caracterizar el corrido acudiendo a particularidades que ya había ubicado al referirse a las canciones y los poemas sobre la guerra, como la de ser un mecanismo útil para instalar en la memoria social el papel de los individuos que actuaron como dirigentes o combatientes rasos.

El tercer bloque de la tesis se refiere a los contenidos temáticos de las composiciones. Al respecto, Villanueva Martínez indica que los temas alusivos fueron variados y expresaron diferentes momentos del proceso insurgente y de sus actores. Por ejemplo, resalta la reiteración de la muerte de Gaitán y la violencia promovida por los gobiernos conservadores de Ospina, Gómez y Urdaneta, lo cual sirvió de argumento para explicar la violencia en los llanos orientales y para justificar el levantamiento insurgente. También las letras de las composiciones evocaban de manera reiterada el papel de los dirigentes guerrilleros, a quienes se les veía como ejecutores de una justicia de cariz popular, permitiendo de ese modo que se crearan y fortalecieran mitos en torno a ellos. Sobre esto último, Villanueva Martínez resalta que las letras de las canciones y los poemas estaban mediatizadas por elementos religiosos y deseos de venganza de una población que se asumía como víctima de una violencia oficial. 
Si bien anotamos que en la presentación de Canciones de la guerra se suelen repetir tesis sobre sus funciones y la evocación de temas como la figura de Guadalupe Salcedo, hay que agregar que algunas líneas de la interpretación del autor merecen mayor profundidad en su descripción y articulación con las composiciones, como la idea de que estas se constituyeron en discursos ocultos. Lo anterior no resta méritos a la publicación de Villanueva Martínez, la cual es, sin duda, un gran aporte al conocimiento de la insurrección llanera de mediados del siglo XX. Varias serían las razones que podrían resaltarse para justificar esa valoración. Por ejemplo, al poner la mirada en las composiciones musicales y los poemas, el autor destaca la importancia de las manifestaciones culturales en la trama de los acontecimientos -en este caso, la insurrección- en que se vieron envueltos sus protagonistas directos e indirectos. De esta manera reconoce el alto valor que las composiciones musicales y los poemas tienen para comprender analíticamente esos acontecimientos. Concebir la potencialidad de la música como fuente informativa y a la vez como expresión de circunstancias históricas puntuales, repetimos, es uno de los principales aciertos de la publicación. Al respecto, el autor llama la atención, al igual que el prologuista, sobre la fina relación entre música y guerra, que en el caso colombiano no ha despertado mayor interés, algo que no deja de sorprender si no se pierde de vista que las guerras -las del siglo XIX y el siglo XX- han tenido como escenarios regiones con patrones culturales diversos, en donde la música generalmente ha estado presente.

En esa misma dirección, es destacable el argumento que establece el autor acerca de la música como un canal por donde circula la memoria y pretende mantenerse activa, reconociendo que en ese proceso ha ocurrido un blanqueamiento en el discurso oculto que estaba implícito en la letra original de las canciones y los poemas, hecho que es explicado básicamente por razones comerciales. Reunir en un libro una significativa producción de cantos y poemas relativos a la insurrección llanera, en tal sentido, es también un aporte sobresaliente porque, además de demostrar la consistencia que tuvo una práctica social en una región del país, permite su preservación para que las generaciones futuras puedan conocerlas. Al respecto, se debe advertir que esta publicación es el primer ejercicio sistemático de compilación y análisis de las canciones asociadas a la insurrección llanera de mediados del siglo XX, sin que esto signifique que otros trabajos no hayan hecho referencia a composiciones musicales acerca de ese levantamiento armado. ${ }^{3}$

Por último, el libro de Villanueva Martínez adquiere importancia al articularse a investigaciones que viene realizando el autor desde hace varios años, y que han apuntado a recuperar las trayectorias de individuos y colectivos subalternos quienes, por circunstancias históricas, se vieron impulsados a confrontar al Estado y a las elites políticas del país y han sido, si no relegados por la historiografía, abordados con menor intensidad. Al centrar la mirada en las canciones y los poemas asociados a la insurrección llanera de mediados del siglo pasado, Villanueva Martínez precisamente ha llamado la atención sobre las representaciones sociales construidas desde abajo, las cuales se inscriben en las dinámicas de confrontación que libraron actores populares ligados a la vida rural y pueblerina del oriente del país.

\footnotetext{
3 Reinaldo Barbosa ya se había referido, en un texto publicado en 1992, a la importancia del corrido guadalupeño, en la insurrección de los llanos orientales. Ver Hermes Tovar Pinzón, "Reinaldo Barbosa, Guadalupe y sus centauros. Memorias de la insurrección llanera", Anuario Colombiano de Historia Social y de la Cultura, $\mathrm{N}^{\circ} 20$ (1992):169-172.
} 


\section{Bibliografía.}

Tovar Pinzón, Hermes. "Reinaldo Barbosa, Guadalupe y sus centauros. Memorias de la insurrección llanera". Anuario Colombiano de Historia Social y de la Cultura, $\mathrm{N}^{\circ} 20$ (1992):169-172.

Villanueva Martínez, Orlando. Guadalupe Salcedo y la insurrección llanera, 1949 - 1957. Bogotá: Universidad Nacional de Colombia, 2012. 